\title{
A comprehensive approach to handle the dynamics of customer's needs in Quality Function Deployment based on linguistic variables
}

\author{
Zohreh Bostaki $^{a^{*}}$ and Emad Roghanian ${ }^{b}$
}

${ }^{a}$ Department of Industrial Engineering, Science and Research branch, Islamic Azad University, arak, Iran ${ }^{b}$ Department of Industrial Engineering, Khaje Nasir Toosi University of Technology, Tehran, Iran

\section{H R O N I C L E}

Article history:

Received January 15, 2013

Accepted October 12, 2013

Available online

October 192013

Keywords:

Quality Function Deployment

House of quality

Linguistic variables

Group decision-making

Dynamics of customer needs

Future uncertainty

Stochastic dominance

\begin{abstract}
A B S T R A C T
In the contexture of a customer-driven goods or service design process, a well-timed update of customer's requirements may not only serve as a necessity indicator to observe how things change over time, but also it incorporates the firms a better ground to interoperate different strategies to meet the future needs of its customer. This paper proposes a systematic methodology to deal with the customer needs' dynamics, in terms of their relative weights, in the QFD. Compared with previous research, the contribution of this paper is fourfold. First, it applies some linguistic variables to get preferences of customers and experts to determine the relative importance of customer requirements (CRs) and the relationships between customer requirements and engineering characteristics (ECs). Second, it proposes the implementation of a forecasting technique. Third, it describes more comprehensively on how future uncertainty in the weights of customer's needs could be estimated and transmitted into the design attributes. Fourth, it proposes the implementation of a quantitative approach, which takes into account the decision maker's attitude towards risk to optimize the QFD decision making analysis. Finally, a real-world application of QFD is provided to demonstrate the practical applicability of the proposed methodology.
\end{abstract}

\section{Introduction}

Quality Function Deployment (QFD) has been widely recognized as an essential tools in customerdriven products or services development (Akao, 1990; Prasad, 1998; Ho et al., 1999; Han et al., 2004; Wang \& Xiong, 2011; Raharjo et al., 2011). QFD has been widely implemented in different areas of engineering. The most important strength of QFD is its concentration on customer's needs and the coherent translation of their needs into each phase of the product development process. QFD has a knowledge-intensive activity in its process, while available information in early stage of new product

* Corresponding author. Tel: +989133710438

E-mail addresses: zohreh_bostaki_ie@yahoo.com (Z. Bostaki)

(C) 2014 Growing Science Ltd. All rights reserved. doi: $10.5267 /$ j.dsl.2013.10.002 
design are often limited and inaccurate (Raharjo et al., 2011). Therefore, it is too complicated for a decision-maker to determine the necessary description in exact numerical values and it is better to provide the necessary customer's preferences by means of linguistic variables rather than numerical ones. In fact, linguistic terms have been recognized to be more popular in expressing the decision makers' assessments with vagueness and imprecision. With respect to the uncertainty involved, Kim and Kim (2009) recommended a very useful classification. They grouped the source of the uncertainty into four categories, namely, fuzziness, incompleteness, heterogeneity, and fluctuation. In real-world product development problems, the decision makers may face with various cultural and educational backgrounds with different understanding levels of the developing product. Thus, the decision-makers usually provide their preference information using linguistic terms of from linguistic label sets with various granularities (Herrera et al., 2000; Zhang \& Chu, 2009; Kuo et al., 2009). Zhang and Chu (2009) presented a fuzzy GDM method by incorporating two optimization techniques to aggregate multi-format and multi-granularity linguistic judgments in QFD.

Recently, Wang and Xiong (2011) proposed a complete linguistic-based QFD technique, which could enhance the tolerance capability of the calculation results. However, in this study, all the decisionmakers involved in the construction of HOQ were handled equally. Furthermore, due to the estimation inaccuracies, lack of knowledge, and decision-makers' limited expertise associated with the problem domain, the linguistic preference information given by experts are expressed in terms of uncertain linguistic information.

In this study, we propose a direct and complete linguistic-based group decision making (GDM) approach (Bordogna et al., 1997; Liu, 2009) to aggregate these assessments, which is an extension of the method proposed by Wang and Xiong (2011). We concentrate on dealing with the last type of uncertainty, that is, 'fluctuation' in the customer's needs over time. To the best of our knowledge, this is one of the new methods for addressing uncertainty of customer's needs in QFD decision making analysis. This paper elaborates more extensively on how one may, in a more systematic fashion, predict the future uncertainty and eventually apply an optimization technique with respect to it (Raharjo \& Brombacher, 2011). The primary objective of this paper, in general, is to propose a novel systematic methodology to deal with the customer needs' dynamics in QFD (Bhattacharya et al., 1998; Köksal, \& Eğitman, 1998). The term 'dynamics' here is interpreted as the change of customer needs' relative weights over time. Specifically, it will extend the existing research in four directions: First, it applies the linguistic variables to take into account the customers' preferences to detect the relative importance of customer requirements (CRs) and relationships between customer requirements and engineering characteristics (ECs). Second, it explains details of a forecasting technique. Third, it presents more comprehensively on how we can estimate future uncertainty in the weights of customer needs and transmit them into some design attributes. Fourth, it proposes the implementation of a quantitative approach, which takes into account the decision maker's attitude towards risk to optimize the QFD decision making analysis.

The paper is organized as follows. In section 1, we explain the relative importance of incorporating customer needs' dynamics in QFD. We then explain the notion of dynamic QFD (DQFD) in terms of its significance. Section 4 describes some basic concepts of linguistic variables and linguistic label sets. Section 5 describes how to estimate the uncertainty. Section 6 elaborates the proposed systematic methodology to handle the dynamic of customer needs along with their future uncertainty. An instance based on a real-world application of QFD is provided to show how the proposed methodology works in practice (Section 7). Section 8 discusses the issue of forecasting technique's selection and a possible implication of the methodology for development of innovative products. Finally, a summary of the main contribution and possible future works are provided in Section 9. 


\section{Customer needs' dynamics}

QFD starts and ends with the customer and it always take some time to understand when the customer voice is collected until the time when the product is ready to be launched. The time-lag duration may vary from one product to another. For instance, if it takes one year time, then the question is whether the product, which is about to be launched may still meet the customer's needs since it is created based on the customer voice collected several months ago. The answer to this question is most likely negative in the context of today's rapidly changing market. The accuracy of information in the customer's needs, which is also referred to as the Voice of Customer (VOC) in the HoQ, plays essential role on the success of a QFD application (Cristiano et al., 2001). In other words, for a QFD application to be successful, the dynamics of customer's needs or VOC during the product creation process should be taken into account. One way to tackle the change over time problem is to base the QFD analysis on the forecasted VOC, rather than the past VOC.

\section{The DQFD model}

This section describes the notion of dynamic QFD (DQFD) considered as an extension of the standard QFD (Cohen \& Cohen, 1995; Kwong \& Bai, 2003) since it takes into account the change over time. In this paper, the emphasis is placed on the need to deal with the dynamics in the relative weights of customer needs and the weights are commonly referred to as 'importance rating' in the House of Quality (HoQ). The term customer requirements (CRs) and engineering characteristics (ECs) is referred to customer attributes or requirements (Whats) and the design parameters or the technical attributes (Hows), respectively. The dynamic QFD (DQFD) technique extends the input data of the traditional QFD model (Cohen, 1995) by incorporating a set of VOC data, in terms of importance rating values, which are obtained in a certain time. Thus, it is a more generalized model of the traditional QFD. The basic dynamic QFD model for $n$ CRs and $s$ ECs is shown in Fig. 1. A simple row normalization procedure as follows:

$$
\mathrm{R}_{\mathrm{ij}}^{\text {norm }}=\mathrm{R}_{\mathrm{ij}} / \sum_{\mathrm{j}=1}^{\mathrm{s}} \mathrm{R}_{\mathrm{ij}}
$$

The priorities of the ECs in the DQFD model can be measured by taking the product of $\mathrm{R}_{\mathrm{ij}}^{\text {norm }}$ and the forecasted importance rating $\left(I R_{i, k+1}\right)$ is as follows,

$$
\hat{\mu}_{j}=\sum_{i=1}^{n} R_{i j}^{n o r m} \cdot I R_{i, k+1}, i=1, \cdots, j ; j=1, \cdots, s,
$$

where $\hat{\mu}_{j}$ is the mean of forecasted priority of ECj; I R,k+1 is the forecasted importance rating of CRi; $k$ is the last period of observation or number of observations. Those ECs' priorities play essential role to the QFD practitioners because they determine all subsequent decisions and processes. One important idea in the DQFD is to not only include the forecasted point, but also the uncertainty measure (interval) of the forecast. In Fig. 1, the future uncertainty of the forecasted importance rating is stated by the standard deviation of the forecasting residual $\left(\mathrm{Sd}_{\mathrm{i}}\right)$. These $\mathrm{Sd}_{\mathrm{i}}$ values can be converted into the standard deviation of the forecasted priority of $E C j$ based on the principle of variance addition as follows,

$$
\widehat{\sigma}_{\mathrm{j}}=\sqrt{\sum_{\mathrm{i}=1}^{\mathrm{n}} \mathrm{R}_{\mathrm{ij}}^{\text {norm }} \cdot \widehat{\sigma}_{\mathrm{i}}^{2}} \forall \mathrm{j}=1,2, \ldots, \mathrm{s},
$$


where $\widehat{\sigma}_{j}$ is the standard deviation of forecasted priority of $E C_{j}$ and $\widehat{\sigma}_{i}^{2}$ is the variance of the forecasting residual of $I R_{i}$ or the squared value of $\mathrm{Sd}_{\mathrm{i}}$. Note that such computation may slightly reduce the value of the transmitted variance due to the multiplication of normalized scores $R_{i j}^{\text {norm }}$.

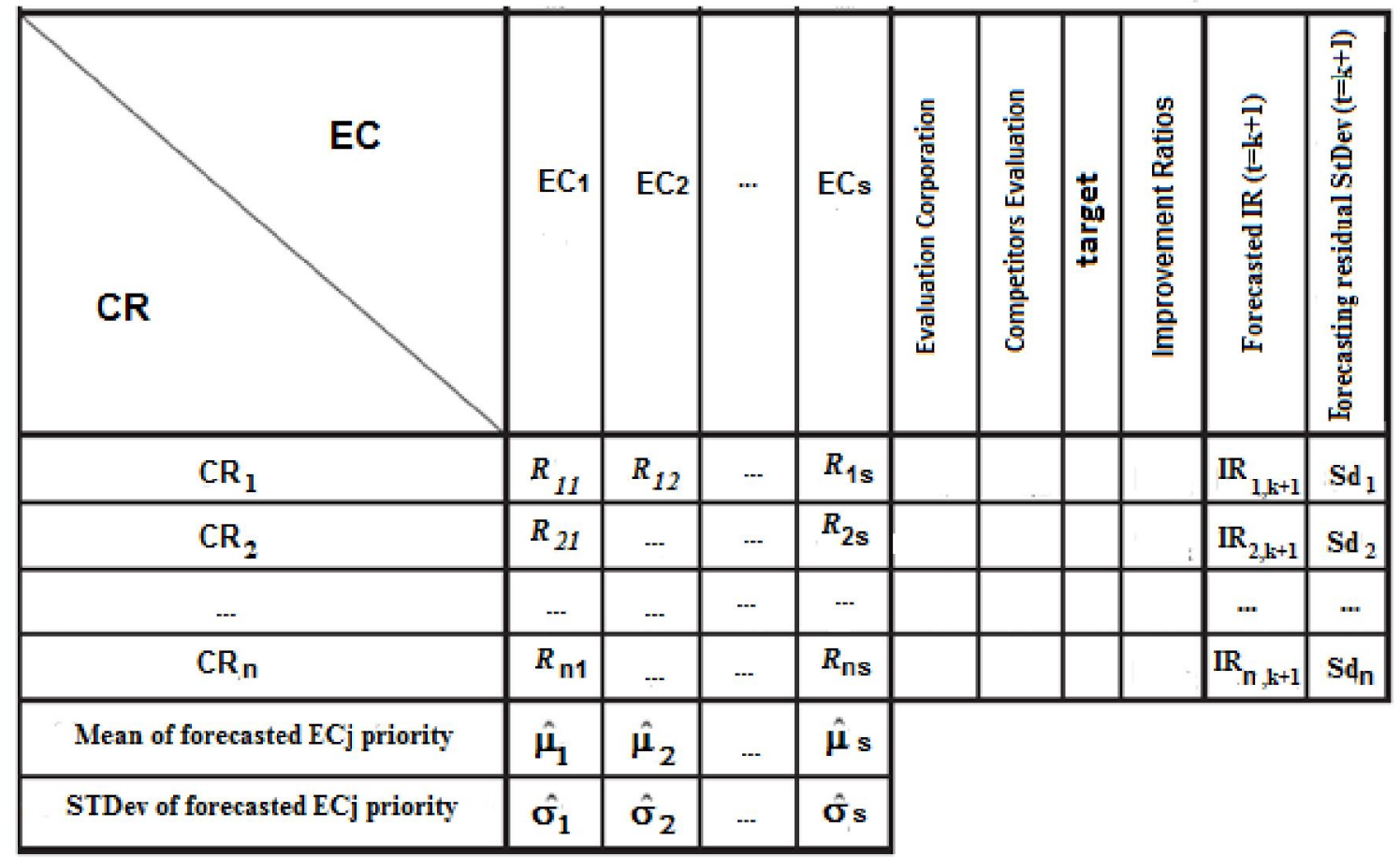

Fig. 1. The DQFD model.

\section{Linguistic label sets and linguistic variables}

In many real-world QFD applications, customers or product developers usually provide their perception, judgment and evaluation with linguistic terms, which could be stated as uniform and symmetrically distributed. However, in group negotiation process, which is a typical process in the building of HOQ, the unbalanced linguistic information appears due to the nature of the linguistic variables implemented in many problems (Herrera et al., 2000). Xu (2009) proved that for the same deadline of acceptable similarity, the group consensus degree achieved from the unbalanced linguistic label sets (ULLS) is relatively higher than that from the balanced linguistic label sets (BLLS). As a result, compared with the BLLS, the ULLS needs less interaction attempts in the process of group consensus reaching, and are more suitable to be applied in product development processes. Here, an unbalanced linguistic label set (ULLS) S(k) is defined as follows (Xu, 2009):

$\mathrm{S}^{(\mathrm{k})}=\left\{\mathrm{S}_{\alpha}^{(\mathrm{k})} \mid \alpha=1-\mathrm{k}, \frac{2}{3}(2-\mathrm{k}), \frac{2}{4}(3-\mathrm{k}), \ldots, 0, \ldots, \frac{2}{4}(\mathrm{k}-3), \frac{2}{3}(\mathrm{k}-2), \mathrm{k}-1\right\}$,

where $k$ is a positive integer and $\mathrm{S}_{\alpha}^{(\mathrm{k})}$ represents a possible value for a linguistic label and the mid linguistic label $\mathrm{S}_{0}^{(\mathrm{k})}$ represents an assessment of "neutral". $\mathrm{S}^{(\mathrm{k})}$ is a finite and totally ordered discrete label set, while $\mathrm{S}_{1-\mathrm{k}}^{(\mathrm{k})}$ and $\mathrm{S}_{\mathrm{k}-1}^{(\mathrm{k})}$ represent the left and right bounds of the linguistic labels in $\mathrm{S}^{(\mathrm{k})}$, respectively. The cardinality value of $S^{(\mathrm{k})}$ is $2 \mathrm{k}-1$, and $\mathrm{S}^{(\mathrm{k})}$ satisfies the following conditions:

(1) $\mathrm{S}_{\alpha}^{(\mathrm{k})}>\mathrm{S}_{\beta}^{(\mathrm{k})}$ iff $\alpha>\beta$;

(2) There is the negation operation: $\operatorname{neg}\left(\mathrm{S}_{\alpha}^{(\mathrm{k})}\right)=\mathrm{S}_{-\alpha}^{(\mathrm{k})}$, especially, $\operatorname{neg}\left(\mathrm{S}_{0}^{(\mathrm{k})}\right)=\mathrm{S}_{0}^{(\mathrm{k})}$. 
For instance, to compute the relative importance of CRs, the relationship between CRs and ECs, and the correlation among ECs, a set of five linguistic labels $\mathrm{S}^{(3)}$ could be (Fig. 2): a set of seven linguistic labels $\mathrm{S}^{(4)}$ could be (Fig. 3): and a set of nine linguistic labels $\mathrm{S}^{(5)}$ could be (Fig. 4):

$\begin{array}{ccccc}\begin{array}{c}\text { Very unimportant/ } \\ \text { Very harmful }\end{array} & \begin{array}{c}\text { Unimportant/ } \\ \text { Harmful }\end{array} & \begin{array}{c}\text { Fair/ } \\ \text { Neutral }\end{array} & \begin{array}{c}\text { Important/ } \\ \text { Useful }\end{array} & \begin{array}{c}\text { Very important/ } \\ \text { Very useful }\end{array} \\ \mathrm{S}_{-2}^{(3)} & \mathrm{S}_{-2 / 3}^{(3)} & \mathrm{S}_{0}^{(3)} & \mathrm{S}_{2 / 3}^{(3)} & \mathrm{S}_{2}^{(3)}\end{array}$

Fig. 2. A set of five linguistic labels $S(3)$

\begin{tabular}{|c|c|c|c|c|c|c|}
\hline $\begin{array}{c}\text { Very } \\
\text { unimportant/ } \\
\text { Very harmful }\end{array}$ & $\begin{array}{l}\text { Unimportant/ } \\
\text { Harmful }\end{array}$ & $\begin{array}{c}\text { Slightly } \\
\text { unimportant/ } \\
\text { Slightly } \\
\text { harmful }\end{array}$ & $\begin{array}{c}\text { Fair/ } \\
\text { Neutral }\end{array}$ & $\begin{array}{c}\text { Slightly } \\
\text { important/ } \\
\text { Slightly } \\
\text { useful }\end{array}$ & $\begin{array}{l}\text { Important/ } \\
\text { Useful }\end{array}$ & $\begin{array}{c}\text { Very } \\
\text { important/ } \\
\text { Very usefu }\end{array}$ \\
\hline$S_{-3}^{(4)}$ & $\mathrm{S}_{-4 / 3}^{(4)}$ & $S_{-1 / 2}^{(4)}$ & $\mathrm{S}_{0}^{(4)}$ & $\mathrm{S}_{1 / 2}^{(4)}$ & $\mathrm{S}_{4 / 3}^{(4)}$ & $\mathrm{S}_{3}^{(4)}$ \\
\hline
\end{tabular}

Fig. 3. A set of seven linguistic labels $\mathrm{S}(4)$

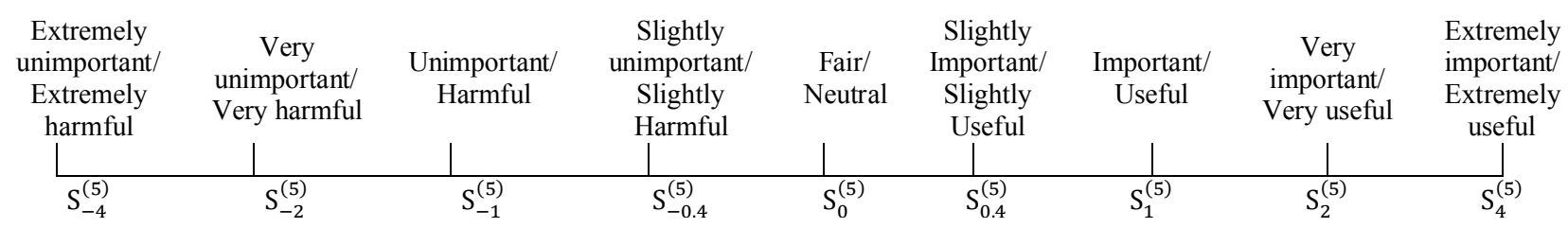

Fig. 4. A set of nine linguistic labels S(5)

More specifically, the relative importance of CRs is analyzed based on upper linguistic terms, i.e., 'very unimportant', 'important', and 'very important', while the relationships between CRs and ECs are computed based on lower linguistic terms, i.e., 'very harmful', 'harmful', and 'very useful' in Figs. 2-4, respectively. To preserve all the given decision information, Xu (2005) extended the discrete linguistic label set $S^{(k)}$ to a continuous label set $\bar{S}^{(k)}=\left\{S_{\alpha}^{(k)} \mid \alpha \in[-t, t]\right\}$, where $t(t>k)$ is a sufficiently large positive integer. If $S_{\alpha}^{(\mathrm{k})} \in S^{(\mathrm{k})}$, then $S_{\alpha}^{(\mathrm{k})}$ is termed an original linguistic label, otherwise, $S_{\alpha}^{(k)}$ is termed a virtual linguistic label. Generally, the virtual linguistic labels can only appear in calculations. Consider any two linguistic terms $S_{\alpha_{1}}^{(k)}, S_{\alpha_{2}}^{(k)} \in \bar{S}^{(k)}$, and $\lambda, \lambda_{1}, \lambda_{2} \in[0,1]$, some operational laws are described as follows (Xu, 2005):

(1) $\mathrm{S}_{\alpha_{1}}^{(\mathrm{k})} \oplus \mathrm{S}_{\alpha_{2}}^{(\mathrm{k})}=\mathrm{S}_{\alpha_{2}}^{(\mathrm{k})} \oplus \mathrm{S}_{\alpha_{1}}^{(\mathrm{k})}=\mathrm{S}_{\alpha_{1}+\alpha_{2}}^{(\mathrm{k})}$;

(2) $\lambda S_{\alpha_{1}}^{(\mathrm{k})}=S_{\lambda \alpha_{1}}^{(\mathrm{k})}$;

(3) $\left(\lambda_{1}+\lambda_{2}\right) S_{\alpha}^{(\mathrm{k})}=\lambda_{1} S_{\alpha}^{(\mathrm{k})} \oplus \lambda_{2} S_{\alpha}^{(\mathrm{k})}$;

(4) $\lambda\left(S_{\alpha_{1}}^{(\mathrm{k})} \oplus S_{\alpha_{2}}^{(\mathrm{k})}\right)=\lambda S_{\alpha_{1}}^{(\mathrm{k})} \oplus \lambda S_{\alpha_{2}}^{(\mathrm{k})}$.

Definition 1. Let $\widetilde{S}^{(\mathrm{k})}=\left[\mathrm{S}_{\alpha}^{(\mathrm{k})}, \mathrm{S}_{\beta}^{(\mathrm{k})}\right]$, where $\mathrm{S}_{\alpha}^{(\mathrm{k})}, \mathrm{S}_{\beta}^{(\mathrm{k})} \in \overline{\mathrm{S}}^{(\mathrm{k})}, \mathrm{S}_{\alpha}^{(\mathrm{k})}$ and $\mathrm{S}_{\beta}^{(\mathrm{k})}$ are the left and right bounds of $\widetilde{S}^{(k)}$, respectively. Then $\widetilde{S}^{(k)}$ is named an uncertain linguistic variable (Xu, 2004). For computational convenience, let $\widetilde{\mathrm{S}}^{(\mathrm{k})}$ be the set of all the uncertain linguistic variables corresponding to the linguistic label set $\mathrm{S}^{(\mathrm{k})}$. 
Definition 2. Let $S_{\alpha}^{(k)}, S_{\beta}^{(k)} \in \bar{S}^{(k)}$, then the deviation degree between $S_{\alpha}^{(k)}$ and $S_{\beta}^{(k)}$ is defined as follows $(\mathrm{Xu}, 2005)$ :

$\mathrm{d}\left(\mathrm{S}_{\alpha}^{(\mathrm{k})}, \mathrm{S}_{\beta}^{(\mathrm{k})}\right)=\frac{|\alpha-\beta|}{2 \mathrm{k}-1}$,

where $2 \mathrm{k}-1$ is the cardinality value of ULLS $\overline{\mathrm{S}}^{(\mathrm{k})}$. Obviously, $0 \leq \mathrm{d}\left(\mathrm{S}_{\alpha}^{(\mathrm{k})}, \mathrm{S}_{\beta}^{(\mathrm{k})}\right) \leq 1$, especially, if $\mathrm{d}\left(\mathrm{S}_{\alpha}^{(\mathrm{k})}, \mathrm{S}_{\beta}^{(\mathrm{k})}\right)=0$, then $\mathrm{S}_{\alpha}^{(\mathrm{k})}=\mathrm{S}_{\beta}^{(\mathrm{k})}$

Definition 3. Let $\left(S_{\alpha_{1}}^{(\mathrm{k})}, S_{\alpha_{2}}^{(\mathrm{k})}, \ldots, \mathrm{S}_{\alpha_{\mathrm{m}}}^{(\mathrm{k})}\right) \in \overline{\mathrm{S}}^{(\mathrm{k})}$ be a set of linguistic variables to aggregate and $\left(\mathrm{w}_{1}, \mathrm{w}_{2}, \ldots, \mathrm{w}_{\mathrm{m}}\right)$ be the weighting vector, with $0 \leq \mathrm{w}_{\mathrm{i}} \leq 1$ and $\sum_{\mathrm{i}=1}^{\mathrm{m}} \mathrm{w}_{\mathrm{i}}=1$, then the linguistic weighted arithmetic averaging (LWAA) operator is expressed as (Xu, 2008):

$\operatorname{LWAA}_{\mathrm{w}}\left(\mathrm{S}_{\alpha_{1}}^{(\mathrm{k})}, \mathrm{S}_{\alpha_{2}}^{(\mathrm{k})}, \ldots, \mathrm{S}_{\alpha_{\mathrm{m}}}^{(\mathrm{k})}\right)=\oplus_{\mathrm{i}=1}^{\mathrm{m}}\left(\mathrm{w}_{\mathrm{i}} \mathrm{S}_{\alpha_{\mathrm{i}}}^{(\mathrm{k})}\right)$

This linguistic aggregation operator can compute with words $(\mathrm{CW})$ directly, which will avoid the risk of loss of information.

\section{Estimation of future uncertainty}

The rationale of future uncertainty's estimation is constructed based on the idea of how well one may learn from the past experience, that is, how precisely one can model or learn from the past data may critically determine how precisely one may estimate or understand the future. Thus, we recommend to estimate the future uncertainty from the fitting imprecision of the forecasting model. For the forecasting technique, the Euclidean distance, which is a scalar quantity, is used as the primary yardstick to judge the goodness of fit of the model. For a given time $t$, the measure of discrepancy between the actual importance rating values (IR) and the fitted ones (I' $\mathrm{R}$ for $\left(\mathrm{CR}_{\mathrm{i}}, i=1, \ldots, n\right)$ is as follows:

$A d_{i}\left(I R, I R^{\prime}\right)=\left(I R-I R^{\prime}\right)$

Note that the sum of all the $n$ IR values, for a given time $t$, is equal to 1 . After computing the forecasting residual, the forecasted points along with their variances are transmitted to the ECs' priorities using Eq. (2) and (3). Since a linear combination of several normal random variables is also normal distributed, the forecasted EC's priorities, which are shown in the last two rows of Fig. 2, can be regarded as several normally distributed processes with a mean value of $\hat{\mu}_{j}$ and a standard deviation value of $\widehat{\sigma}_{j}$. Thus, the problem is now how one may prioritize or optimize those ECs with respect to their mean and standard deviation values.

\section{The proposed methodology}

The objective of the proposed methodology is to provide a systematic approach, which takes into account the decision maker's attitude towards risk, to deal with the dynamics of customer needs. A step-by-step procedure, starting from the construction of the DQFD until the prioritization stage is provided in Fig. 5. The stochastic ordering reflects the preference of the decision maker on the QCs. In this paper, the stochastic ordering result is used as the basis for resource allocation in the sense that it restricts the amount of resources allocated among the QCs. To show how the stochastic dominance results can be applied in an optimization framework, a simple customer satisfaction optimization model is adopted (Levy, 1998). 


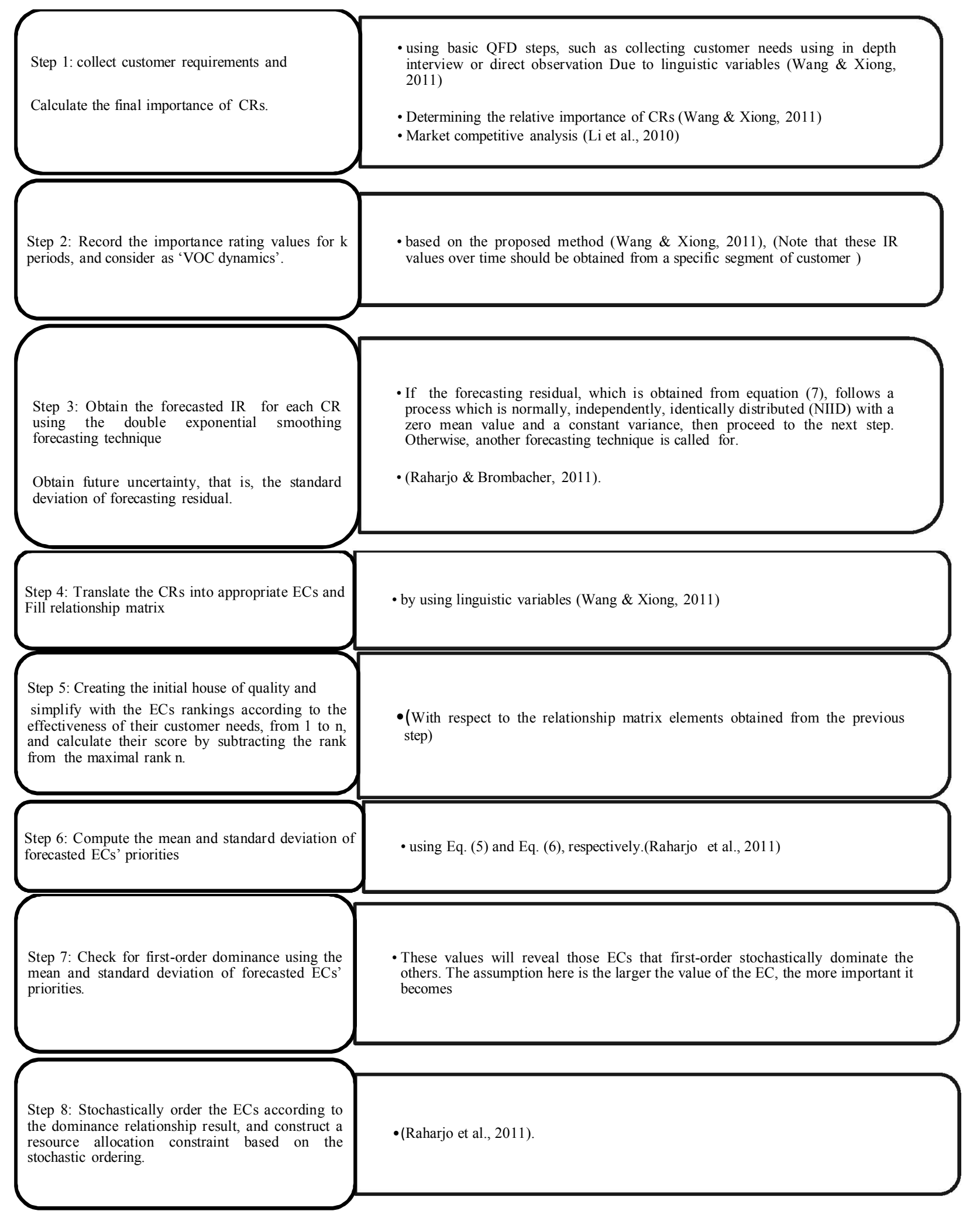

Fig. 5. The proposed methodology

The objective is to maximize the total customer satisfaction $(Z)$ by optimizing the available resources, for example, the allocated cost for each $\mathrm{EC}$ with respect to its target value. The complete optimization model is given in Eqs. (9-13). The stochastic dominance result, namely, the stochastic ordering of the 
ECs, is translated into Eq. (12). It is worth noting that the value of $Z$ will only range from zero to one, with " 0 " indicates total dissatisfaction and " 1 " maximum total customer satisfaction.

Maximize $Z=\sum_{j=1}^{n} \sum_{i=1}^{m} I R_{i, k+1} R_{i j}^{\text {norm }} X_{j} / C_{j}$.

subject to

$\sum_{j=1}^{n} x_{j} \leq B$

$\sum_{j=1}^{n} R_{i j}^{\text {norm }} . X_{j} / C_{j} \geq S L_{i} \forall i=1,2, \ldots, m$.

$\mathrm{X}_{\mathrm{a}} / \mathrm{C}_{\mathrm{a}}-\mathrm{X}_{\mathrm{b}} / \mathrm{C}_{\mathrm{b}} \geq \delta_{\mathrm{r}}$ if $\exists \mathrm{QC}_{\mathrm{a}}>_{(0)} \mathrm{QC}_{\mathrm{b}} \quad \forall \mathrm{a}, \mathrm{b}=1,2, \ldots, \mathrm{n}$,

$0 \leq \mathrm{X}_{\mathrm{j}} / \mathrm{C}_{\mathrm{j}} \leq 1$

where $X_{j}$ the amount of resource/cost allocated to $E_{j} ; C_{j}$ the cost required to increase $E_{j}$ to its target value; $\mathrm{B}$ the amount of budget available for quality improvement; $I R_{i, k+1}$ forecasted importance rating value of $\mathrm{CR}_{i}$; $\mathrm{SL}_{\mathrm{i}}$ minimum satisfaction level of $\mathrm{CR}_{\mathrm{i}}$; o order of dominance; $\delta_{\mathrm{r}}$ the minimal difference of fulfillment between two corresponding ECs. The subscript $\mathrm{r}$ is used to allow various values for the difference between the two ECs.

\section{An example}

This section provides an example of how one may apply the proposed methodology by following the step-by-step procedure described. The example is based on a real-world case study of a QFD application in improving product quality Alternator sets in Poya Sanaat manufacturing company .This company produces Alternator sets and provides it for four of its customers $\left(\operatorname{CUST}_{\mathrm{q}} q=(1,2,3,4)\right)$. Input on proposed methodology is prioritizing customer requirements over time and house of quality of Alternator set, and the output is prioritized engineering characteristics. The optimization model is used, and the final output is the amount of resources or funds allocated to engineering characteristics. 8 -step process is as follows:

The input of the methodology is the CRs' priority data over time and the HoQ of, and the output is the prioritized ECs. Then the final output is the amount of resources or budget allocated to ECj.

Step 1: The customer requirements were collected through one-on-one interview, and questionnaires. there are eight $\operatorname{CRs}(\mathrm{i}=(1,2,3,4,5,6,7,8))$ (Table 1$)$. The weight vector of customer can be determined as $w=(.25, .25, .25, .25)$.

\section{Table 1}

Customer requirements

\begin{tabular}{|c|c|c|c|}
\hline Symbol & Customer requirements & Symbol & Customer requirements \\
\hline $\mathrm{CR}_{1}$ & $\begin{array}{c}\text { Raising the generator's ampacity at } \\
\text { idle(idl) }\end{array}$ & $\mathrm{CR}_{5}$ & Appropriate Appearance \\
\hline $\mathrm{CR}_{2}$ & $\begin{array}{l}\text { Put down the regulator's temperature } \\
\text { compensated rank }\end{array}$ & $\mathrm{CR}_{6}$ & $\begin{array}{l}\text { Proper functioning of the generator's isolated } \\
\text { cover }\end{array}$ \\
\hline $\mathrm{CR}_{3}$ & Packaging products better & $\mathrm{CR}_{7}$ & Using plumbed lacquer in product assembly \\
\hline $\mathrm{CR}_{4}$ & Using Auto standards (upon customer) & $\mathrm{CR}_{8}$ & Increasing the generator's efficiency \\
\hline
\end{tabular}

In order to demonstrate the proposed approach, suppose that customer representatives $C_{\text {aST }}$ $q=(1,2,3,4)$ compare each pair of these CRs by using the following different ULLS: 


$$
\begin{aligned}
& \operatorname{CUST}_{1}, \operatorname{CUST}_{4}: \mathrm{S}^{(4)}=\left\{\mathrm{S}_{-3}^{(4)}, \mathrm{S}_{-4 / 3}^{(4)}, \mathrm{S}_{-1 / 2}^{(4)}, \mathrm{S}_{0}^{(4)}, \mathrm{S}_{1 / 2}^{(4)}, \mathrm{S}_{4 / 3}^{(4)}, \mathrm{S}_{3}^{(4)}\right\} \\
& \operatorname{CUST}_{2}: S^{(3)}=\left\{\mathrm{S}_{-2}^{(3)}, \mathrm{S}_{-2 / 3}^{(3)}, \mathrm{S}_{0}^{(3)}, \mathrm{S}_{2 / 3}^{(3)}, \mathrm{S}_{2}^{(3)}\right\} \\
& \operatorname{CUST}_{3}: S^{(5)}=\left\{\mathrm{S}_{-4}^{(5)}, \mathrm{S}_{-2}^{(5)}, \mathrm{S}_{-1}^{(5)}, \mathrm{S}_{-0.4}^{(5)}, \mathrm{S}_{0}^{(5)}, \mathrm{S}_{0.4}^{(5)}, \mathrm{S}_{1}^{(5)}, \mathrm{S}_{2}^{(5)}, \mathrm{S}_{4}^{(5)}\right\}
\end{aligned}
$$

Furthermore, assume that $\mathrm{CUST}_{1}, \mathrm{CUST}_{3}$ and $\mathrm{CUST}_{4}$ construct the traditional linguistic pairwise comparison matrixes by using traditional unbalanced linguistic variables, while $\mathrm{CUST}_{2}$ constructs uncertain linguistic pairwise comparison matrixes by using uncertain unbalanced linguistic variables. The original linguistic evaluations provided by the four customers are given as follows:

\begin{tabular}{|c|c|c|c|c|c|c|c|}
\hline$\left[S^{(3)}{ }_{0}^{(3)}{ }_{0}\right]$ & {$\left[S^{(3)}{ }_{2 / 3} S^{(3)}{ }_{2}\right]$} & {$\left[S^{(3)}{ }_{0}^{(3)} S_{2 / 3}^{(3)}\right]$} & {$\left[\begin{array}{ll}S^{(3)}{ }_{0} & S^{(3)} \\
2 / 3\end{array}\right]$} & {$\left[S^{(3)}{ }_{2 / 3} S^{(3)}{ }_{2}\right]$} & {$\left[\begin{array}{ll}S^{(3)}{ }_{0} & S^{(3)} \\
2 / 3\end{array}\right]$} & {$\left[\begin{array}{ll}(3) & S_{0}^{(3)} \\
S^{(3)}\end{array}\right]$} & {$\left[\mathrm{S}^{(3)}{ }_{0} \mathrm{~S}^{(3) / 3}\right]$} \\
\hline$\left[\begin{array}{ll}{\left[S^{(3)}\right.} & S^{(3)} \\
-2 / 3\end{array}\right]$ & {$\left[S^{(3)}{ }_{0} S^{(3)}{ }_{0}\right]$} & {$\left[\begin{array}{lll}(3) & S_{0}^{(3)} \\
2 / 3\end{array}\right]$} & {$\left[\begin{array}{lll}{[(3)} & S_{0}^{(3)} \\
S_{2 / 3}\end{array}\right]$} & {$\left[\begin{array}{lll}{\left[S^{(3)}\right.} & S^{(3)} \\
2 / 3\end{array}\right]$} & {$\left[\begin{array}{lll}{\left[S^{(3)}\right.} & S^{(3)} \\
2 / 3\end{array}\right]$} & {$\left[\begin{array}{lll}{[(3)} & S^{(3)} & S_{2 / 3}\end{array}\right]$} & {$\left[\begin{array}{ll}\mathrm{S}^{(3)}{ }_{0} \mathrm{~S}^{(3)} & 2 / 3\end{array}\right]$} \\
\hline $\begin{array}{l}{\left[S^{(3)}-2 / 3 S^{(3)} 0\right]} \\
{\left[S^{(3)}-2 / 3 S^{(3)} 0\right]}\end{array}$ & $\left.\begin{array}{l}{\left[S^{(3)}\right.} \\
{\left[S^{(3)}{ }^{-2 / 3} S^{(3)} S^{(3)}\right]}\end{array}\right]$ & $\begin{array}{c}{\left[S^{(3)} S^{(3)}\right]} \\
{\left[S^{(3)}{ }^{(3 / 3} S^{(3)}\right]}\end{array}$ & $\begin{array}{c}{\left[\begin{array}{cc}S^{(3)} & S^{(3)} \\
{\left[S^{(3)}\right.} & S^{(3)}\end{array}\right]} \\
S^{(3)}\end{array}$ & $\begin{array}{l}{\left[S^{(3)} 2 / 3 S^{(3)}\right.} \\
{\left[S^{(3)} S^{(3)}{ }^{(3)} 2 / 3\right]}\end{array}$ & 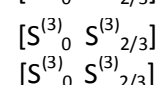 & $\begin{array}{l}{\left[S^{(3)} 2 / 3 S^{(3)}\right.} \\
{\left[S^{(3)} S^{(3)}\right]}\end{array}$ & \\
\hline$\left[\begin{array}{lll}S^{(3)} & -2 & S^{(3)} \\
-2 / 3\end{array}\right]$ & {$\left[\mathrm{S}^{(3)}{ }_{-2 / 3} \mathrm{~S}^{(3)}{ }_{0}\right]$} & {$\left[S^{(3)}{ }_{-2} S^{(3)}{ }_{-2 / 3}\right]$} & {$\left[S^{(3)}{ }_{-2 / 3} S^{(3)}{ }_{0}\right]$} & {$\left[S^{(3)}{ }_{0}^{(3)}{ }_{0}\right]$} & {$\left[\begin{array}{ll}S^{(3)} & S_{0}^{(3)} \\
S_{2 / 3}\end{array}\right]$} & {$\left[S^{(3)}{ }_{2 / 3} S^{(3)}{ }_{2}\right]$} & (3) $2 / 3]$ \\
\hline$\left[S^{(3)}{ }_{-2 / 3} S^{(3)} 0\right]$ & {$\left[\mathrm{S}^{(3)}{ }_{-2 / 3} \mathrm{~S}^{(3)}{ }_{0}\right]$} & {$\left[S^{(3)}{ }_{-2 / 3} S^{(3)}{ }_{0}\right]$} & & & {$\left[\mathrm{S}^{(3)}{ }_{0} \mathrm{~S}_{0}^{(3)}\right]$} & {$\left[\mathrm{S}^{(3)}{ }_{0}\right.$} & \\
\hline & & {$\left[S^{(3)}{ }_{-2} S^{(3)}{ }_{-2 / 3}\right]$} & & {$\left[S^{(3)}{ }_{-2}^{(3)} S_{-2 / 3}^{(3)}\right]$} & {$\left[S^{(3)}{ }_{-2 / 3} S^{(3)}{ }_{0}\right]$} & {$\left[\mathrm{S}^{(3)}{ }_{0} \mathrm{~S}^{(3)}{ }_{0}\right]$} & \\
\hline$\left[\mathrm{S}^{(3)}{ }_{-2 / 3} \mathrm{~S}^{(3)}\right]$ & {$\left[S^{(3)}{ }_{-2 / 3} S^{(3)}{ }_{0}\right]$} & {$\left[S^{(3)}{ }_{-2 / 3} S^{(3)}{ }_{0}\right]$} & {$\left[S^{(3)}{ }_{-2} S^{(3)}{ }_{-2 / 3}\right]$} & {$\left[S^{(3)}{ }_{-2 / 3} S_{0}^{(3)}\right]$} & {$\left[S^{(3)}{ }_{-2 / 3} S^{(3)}{ }_{0}\right]$} & {$\left[S^{(3)}{ }_{-2 / 3} S^{(3)}{ }_{0}\right]$} & {$\left[\begin{array}{ll}S^{(3)} & S^{(3)}\end{array}\right]$} \\
\hline
\end{tabular}

$A_{I}=\left|\begin{array}{cccccccc}S^{(4)} & S^{(4)}{ }_{1 / 2} & S^{(4)}{ }_{0} & S^{(4)}{ }_{1 / 2} & S^{(4)}{ }_{4 / 3} & S^{(4)}{ }_{0} & S^{(4)}{ }_{0} & S^{(4)}{ }_{4 / 3} \\ S^{(4)}{ }_{-1 / 2} & S^{(4)}{ }_{0} & S^{(4)}{ }_{3} & S^{(4)}{ }_{1 / 2} & S^{(4)}{ }_{4 / 3} & S^{(4)}{ }_{1 / 2} & S^{(4)}{ }_{0} & S^{(4)}{ }_{4 / 3} \\ S^{(4)}{ }_{0} & S^{(4)}{ }_{-3} & S^{(4)}{ }_{0} & S^{(4)}{ }_{0} & S^{(4)}{ }_{4 / 3} & S^{(4)}{ }_{1 / 2} & S^{(4)}{ }_{3} & S^{(4)}{ }_{0} \\ S^{(4)}{ }_{-1 / 2} & S^{(4)}{ }_{-1 / 2} & S^{(4)}{ }_{0} & S^{(4)}{ }_{0} & S^{(4)}{ }_{1 / 2} & S^{(4)}{ }_{1 / 2} & S^{(4)}{ }_{0} & S^{(4)}{ }_{4 / 3} \\ S^{(4)}{ }_{-4 / 3} & S^{(4)}{ }_{-4 / 3} & S^{(4)}{ }_{-4 / 3} & S^{(4)}{ }_{-1 / 2} & S^{(4)}{ }_{0} & S^{(4)}{ }_{0} & S^{(4)}{ }_{4 / 3} & S^{(4)}{ }_{0} \\ S^{(4)}{ }_{0} & S^{(4)}{ }_{-1 / 2} & S^{(4)}{ }_{-1 / 2} & S^{(4)}{ }_{-1 / 2} & S^{(4)}{ }_{0} & S^{(4)}{ }_{0} & S^{(4)}{ }_{0} & S^{(4)}{ }_{1 / 2} \\ S^{(4)}{ }_{0} & S^{(4)}{ }_{0} & S^{(4)}{ }_{-3} & S^{(4)}{ }_{0} & S^{(4)}{ }_{-4 / 3} & S^{(4)}{ }_{0} & S^{(4)}{ }_{0} & S^{(4)}{ }_{0} \\ S^{(4)}{ }_{-4 / 3} & S^{(4)}{ }_{-4 / 3} & S^{(4)}{ }_{0} & S^{(4)}{ }_{-4 / 3} & S^{(4)}{ }_{0} & S^{(4)}{ }_{-1 / 2} & S^{(4)}{ }_{0} & S^{(4)}{ }_{0}\end{array}\right|$

\begin{tabular}{|c|c|c|c|c|c|c|c|}
\hline $\mathrm{A}_{3}=$ & $\begin{array}{c}S^{(5)}{ }_{0} \\
S^{(5)}{ }^{-1} \\
S^{(5)}{ }^{-0.4} \\
S^{(5)}{ }^{-1} \\
S^{(5)}{ }^{-0.4} \\
S^{(5)}{ }_{0} \\
S^{(5)}{ }_{0.4}^{0.4} \\
S^{(5)}{ }_{-2}\end{array}$ & $\begin{array}{c}S^{(5)}{ }_{1} \\
S^{(5)}{ }_{0} \\
S^{(5)}{ }^{0.4} \\
S^{(5)}{ }^{-1} \\
S^{(5)}{ }_{0} \\
S^{(5)}{ }^{0.4} \\
S^{(5)}{ }_{0} \\
S^{(5)}{ }_{-2}\end{array}$ & $\begin{array}{c}\mathrm{S}^{(5)}{ }_{0.4} \\
\mathrm{~S}^{(5)}{ }^{-0.4} \\
\mathrm{~S}^{(5)}{ }_{0} \\
\mathrm{~S}^{(5)}{ }^{-0.4} \\
\mathrm{~S}^{(5)}{ }^{0.4} \\
\mathrm{~S}^{(5)}{ }^{0} \\
\mathrm{~S}^{(5)}{ }_{-2} \\
\mathrm{~S}^{(5)}{ }_{0.4}\end{array}$ & $\begin{array}{c}\mathrm{S}^{(5)}{ }_{1} \\
\mathrm{~S}^{(5)}{ }_{1} \\
\mathrm{~S}^{(5)}{ }^{0.4} \\
\mathrm{~S}^{(5)}{ }_{0} \\
\mathrm{~S}^{(5)}{ }_{0} \\
\mathrm{~S}^{(5)}{ }^{-0.4} \\
\mathrm{~S}^{(5)}{ }_{0} \\
\mathrm{~S}^{(5)}{ }_{-0.4}\end{array}$ & $\begin{array}{c}\mathrm{S}^{(5)}{ }_{0.4} \\
\mathrm{~S}^{(5)}{ }_{0} \\
\mathrm{~S}^{(5)}{ }^{-0.4} \\
\mathrm{~S}^{(5)}{ }^{0} \\
\mathrm{~S}^{(5)}{ }_{0} \\
\mathrm{~S}^{(5)}{ }^{0.4} \\
\mathrm{~S}^{(5)}{ }^{-1} \\
\mathrm{~S}^{(5)}{ }_{0.4}\end{array}$ & $\begin{array}{c}\mathrm{S}^{(5)}{ }_{0} \\
\mathrm{~S}^{(5)}{ }^{-0.4} \\
\mathrm{~S}^{(5)}{ }_{0} \\
\mathrm{~S}^{(5)}{ }^{0.4} \\
\mathrm{~S}^{(5)}{ }^{-0.4} \\
\mathrm{~S}^{(5)}{ }^{0} \\
\mathrm{~S}^{(5)}{ }_{1} \\
\mathrm{~S}^{(5)}{ }_{0}\end{array}$ & $\begin{array}{l}S^{(5)}{ }^{-0.4} \\
S^{(5)}{ }_{0} \\
S^{(5)}{ }_{2} \\
S^{(5)} \\
S^{(5)}{ }_{1} \\
S^{(5)}{ }^{-1} \\
S^{(5)}{ }_{0} \\
S^{(5)}{ }_{1}\end{array}$ \\
\hline $\mathrm{A}_{4}=$ & $\begin{array}{c}S^{(4)}{ }_{0} \\
S^{(4)}{ }_{-4 / 3} \\
S^{(4)}{ }_{0} \\
S^{(4)}{ }^{-1 / 2} \\
S^{(4)}{ }_{0} \\
S^{(4)}{ }_{0} \\
S^{(4)}{ }_{0} \\
S^{(4)}{ }_{-1 / 2}\end{array}$ & $\begin{array}{c}S^{(4)}{ }^{4 / 3} \\
S^{(4)}{ }_{0} \\
S^{(4)}{ }_{0} \\
S^{(4)}{ }^{-1 / 2} \\
S^{(4)}{ }_{0} \\
S^{(4)}{ }_{1 / 2}^{1 / 2} \\
S^{(4)}{ }_{0} \\
S^{(4)}{ }_{-4 / 3}^{4}\end{array}$ & $\begin{array}{c}S^{(4)}{ }_{0} \\
S^{(4)}{ }_{0} \\
S^{(4)}{ }_{0} \\
S^{(4)} \\
S^{(4)}{ }^{-1 / 2} \\
S^{(4)}{ }_{0}^{-4 / 3} \\
S^{(4)}{ }^{-1 / 2} \\
S^{(4)}{ }_{0}\end{array}$ & $\begin{array}{l}S^{(4)}{ }_{1 / 2} \\
S^{(4)}{ }_{1 / 2} \\
S^{(4)} 1 / 2 \\
S^{(4)}{ }_{0} \\
S^{(4)}{ }^{-1 / 2} \\
S^{(4)}{ }^{-1 / 2} \\
S^{(4)}{ }^{-1 / 2} \\
S^{(4)}{ }_{-4 / 3}\end{array}$ & $\begin{array}{c}S^{(4)}{ }_{0} \\
S^{(4)} 0 \\
S^{(4)}{ }^{4 / 3} \\
S^{(4)}{ }^{1 / 2} \\
S^{(4)}{ }_{0} \\
S^{(4)}{ }_{0} \\
S^{(4)}{ }^{-4 / 3} \\
S^{(4)}{ }_{1 / 2}\end{array}$ & $\begin{array}{c}S^{(4)}{ }_{0} \\
S^{(4)}{ }^{-1 / 2} \\
S^{(4)}{ }_{0} \\
S^{(4)}{ }^{1 / 2} \\
S^{(4)}{ }_{0} \\
S^{(4)} 0 \\
S^{(4)}{ }_{0} \\
S^{(4)}{ }_{0}\end{array}$ & $\begin{array}{c}S^{(4)}{ }_{0} \\
S^{(4)}{ }_{0} \\
S^{(4)} 1 / 2 \\
S^{(4)} \\
S^{(4)} \\
S^{(4)} \\
S^{(4)}{ }_{0} \\
S^{(4)}{ }_{0}\end{array}$ \\
\hline
\end{tabular}

\section{$\mathrm{A}_{2}=$}

relative importance ratings of the customer requirements $\mathrm{CR}_{\mathrm{i}}(\mathrm{i}=1, \ldots, 8)$ (Wang \& Xiong, 2011) 
The main competitors for the corporation $\operatorname{Corp}_{1}$ are identified with three corporations, denoted as $\operatorname{Corp}_{\mathrm{s}}(\mathrm{s}=2,3,4)$. In order to understand the product market and its relative position in the market, we ask these 4 selected customers to provide the relative performance estimations for its own product and these three competitors' similar products in terms of these eight customer requirements using the 1-10 scale. According to these assessments, a corporation performance estimation matrix $\mathrm{CPE}=$ $\left(\mathrm{cpe}_{\mathrm{ji}}\right)_{8 \times 4}$ can be obtained by averaging the customers' assessment. Based on the available resource and the relative performances of the three corporations on these eight CRs, Corp ${ }_{1}$ can set improvement targets on each CR to better satisfy these CRs. After various considerations Corp $_{1}$ decides the following performance estimation targets of these CRs using the same 1-10 scale (target column) and it can be used to calculate the relative improvement $\mathrm{ir}_{\mathrm{i}}$ (Table 2).

Table 2

A part of HOQ of the alternator set

\begin{tabular}{lcccccc}
\hline & Corp $_{1}$ & Corp $_{2}$ & Corp $_{3}$ & Corp $_{4}$ & target & ir \\
\hline $\mathrm{CR}_{1}$ & 6.000 & 5.000 & 5.000 & 7.500 & 9.500 & 1.583 \\
$\mathrm{CR}_{2}$ & 4.750 & 6.000 & 6.250 & 7.000 & 6.800 & 1.432 \\
$\mathrm{CR}_{3}$ & 5.500 & 7.500 & 6.500 & 5.250 & 5.800 & 1.055 \\
$\mathrm{CR}_{4}$ & 3.500 & 5.000 & 6.750 & 5.750 & 5.400 & 1.543 \\
$\mathrm{CR}_{5}$ & 7.500 & 5.250 & 5.750 & 7.250 & 8.300 & 1.107 \\
$\mathrm{CR}_{6}$ & 8.000 & 4.250 & 3.250 & 4.000 & 9.000 & 1.125 \\
$\mathrm{CR}_{7}$ & 3.250 & 6.000 & 7.250 & 5.500 & 5.500 & 1.692 \\
$\mathrm{CR}_{8}$ & 6.250 & 6.500 & 6.000 & 5.250 & 7.600 & 1.216 \\
\hline
\end{tabular}

Here CPR and improvement ratios are calculated (Li et al., 2010). Based on the relative weights of CRs and above competitive analysis results Kano's categories for the customer requirements given in Table 3, the final importance ratings of CRs can be computed (Wang \& Xiong, 2011) and the vector of the final importance ratings of CRs is determined as

$$
F=\left(f_{1}, f_{2}, f_{3}, f_{4}, f_{5}, f_{6}, f_{7}, f_{8}\right)=(0.039,0.027,0.012,0.028,0.028,0.026,0.024,0.007)
$$

Step 2: Record the CRs' priority values for $k$ periods. Final importance ratings of CRs obtained from the first step are considered for the first period. Then, a pairwise comparison matrix of customer requirements are created from period 2 to period 9 based on the information available about the target company from 4 customer surveys with the linguistic variables and the importance of customer needs in these periods are obtained (Wang \& Xiong, 2011) and they are registered as the dynamics of VOC. The results are in the first column of Table 3.

Table 3

Competitive analysis results of the CRs

\begin{tabular}{lllll}
\hline & $\boldsymbol{C P \boldsymbol { R } _ { \boldsymbol { i } }}$ & $\boldsymbol{i r}_{\boldsymbol{i}}$ & $\boldsymbol{K C}_{\boldsymbol{i}}$ \\
\hline $\mathrm{CR}_{1}$ & 0.113 & 1.583 & 1.500 \\
$\mathrm{CR}_{2}$ & 0.093 & 1.432 & \\
$\mathrm{CR}_{3}$ & 0.103 & 1.055 & \\
$\mathrm{CR}_{4}$ & 0.139 & 1.543 & \\
$\mathrm{CR}_{5}$ & 0.142 & 1.107 & \\
$\mathrm{CR}_{6}$ & 0.192 & 1.125 & 1.000 \\
$\mathrm{CR}_{7}$ & 0.166 & 1.692 & 1.500 \\
$\mathrm{CR}_{8}$ & 0.053 & 1.216 & 0.000 \\
\hline
\end{tabular}

Step 3: Fit the importance rating data change over time using the double exponential smoothing forecasting technique. The actual CRs' priority data (IR values) for each CR for nine years are shown in the first block-column of Table 4 (Wang \& Xiong, 2011). The data which are shown next to the first block-column (Table 4) are the fitted data using the double exponential smoothing method. 
Table 5 shows the fitting error values which are expressed in terms of Euclidean distance, see formula (8). In the last row of Table 5, the standard deviation of the forecasting residual ('StDev $\mathrm{Ad}_{\mathrm{i}}$ '), which serves as the measure of future uncertainty, is provided for each IR (Raharjo \& Brombacher, 2011).

Table 4

Actual, fitted, forecasted values of all IR

\begin{tabular}{|c|c|c|c|c|c|c|c|c|c|c|c|c|c|c|c|c|}
\hline$t$ & $\mathbf{I R}_{\mathbf{1}}$ & $\mathbf{I R}_{\mathbf{2}}$ & $\mathbf{I R}_{\mathbf{3}}$ & $\mathbf{I R}_{\mathbf{4}}$ & $\mathbf{I R}_{\mathbf{5}}$ & $\mathbf{I R}_{\mathbf{6}}$ & $\mathbf{I R}_{\mathbf{7}}$ & $\mathbf{I R}_{\mathbf{8}}$ & $\mathbf{I R}_{1}^{\prime}$ & $\mathbf{I R}_{\mathbf{2}}$ & $\mathbf{I R}_{3}^{\prime}$ & $\mathbf{I R}_{4}{ }_{4}$ & $\mathbf{I R}_{5}$ & $\mathbf{I R}_{6}^{\prime}$ & $\mathbf{I R}_{7}$ & $\mathrm{IR}_{8}^{\prime}$ \\
\hline 1 & 0.039 & 0.027 & 0.012 & 0.028 & 0.028 & 0.026 & 0.024 & 0.007 & 0.040 & 0.029 & 0.012 & 0.028 & 0.028 & 0.024 & 0.024 & 0.007 \\
\hline 2 & 0.039 & 0.030 & 0.010 & 0.028 & 0.025 & 0.024 & 0.027 & 0.008 & 0.039 & 0.028 & 0.012 & 0.028 & 0.028 & 0.025 & 0.024 & 0.007 \\
\hline 3 & 0.041 & 0.029 & 0.011 & 0.028 & 0.032 & 0.021 & 0.022 & 0.007 & 0.039 & 0.029 & 0.011 & 0.028 & 0.027 & 0.024 & 0.025 & 0.008 \\
\hline 4 & 0.038 & 0.030 & 0.012 & 0.022 & 0.028 & 0.026 & 0.026 & 0.008 & 0.040 & 0.029 & 0.011 & 0.028 & 0.029 & 0.023 & 0.024 & 0.007 \\
\hline 5 & 0.039 & 0.024 & 0.011 & 0.030 & 0.027 & 0.027 & 0.026 & 0.007 & 0.039 & 0.029 & 0.011 & 0.026 & 0.029 & 0.024 & 0.025 & 0.008 \\
\hline 6 & 0.035 & 0.026 & 0.012 & 0.024 & 0.027 & 0.025 & 0.029 & 0.008 & 0.039 & 0.027 & 0.011 & 0.027 & 0.028 & 0.025 & 0.025 & 0.007 \\
\hline 7 & 0.035 & 0.025 & 0.009 & 0.030 & 0.032 & 0.025 & 0.026 & 0.008 & 0.038 & 0.027 & 0.011 & 0.026 & 0.028 & 0.025 & 0.027 & 0.008 \\
\hline 8 & 0.037 & 0.030 & 0.009 & 0.024 & 0.030 & 0.028 & 0.027 & 0.008 & 0.036 & 0.026 & 0.010 & 0.027 & 0.029 & 0.025 & 0.027 & 0.008 \\
\hline 9 & 0.039 & 0.025 & 0.011 & 0.026 & 0.028 & 0.027 & 0.026 & 0.008 & 0.036 & 0.027 & 0.010 & 0.026 & 0.030 & 0.027 & 0.027 & 0.008 \\
\hline 10 & & & & & & & & & 0.037 & 0.026 & 0.010 & 0.026 & 0.029 & 0.027 & 0.027 & 0.008 \\
\hline
\end{tabular}

Table 5

Fitting error values of all IR and standard deviation

\begin{tabular}{|c|c|c|c|c|c|c|c|c|}
\hline $\mathbf{t}$ & $\mathbf{A d}_{1}$ & $\mathbf{A d}_{2}$ & $\mathbf{A d}_{3}$ & $\mathbf{A d}_{4}$ & $\mathbf{A d}_{5}$ & $\mathbf{A d}_{6}$ & $\mathbf{A d}_{7}$ & $\mathbf{A d}_{8}$ \\
\hline 1 & -0.001 & -0.002 & 0.000 & 0.000 & 0.000 & 0.002 & 0.000 & 0.000 \\
\hline 2 & 0.000 & 0.002 & -0.002 & 0.000 & -0.003 & -0.001 & 0.003 & 0.001 \\
\hline 3 & 0.002 & 0.000 & 0.000 & 0.000 & 0.005 & -0.003 & -0.003 & -0.001 \\
\hline 4 & -0.002 & 0.001 & 0.001 & -0.006 & -0.001 & 0.003 & 0.002 & 0.001 \\
\hline 5 & 0.000 & -0.005 & 0.000 & 0.004 & -0.002 & 0.003 & 0.001 & -0.001 \\
\hline 6 & -0.004 & -0.001 & 0.001 & -0.003 & -0.001 & 0.000 & 0.004 & 0.001 \\
\hline 7 & -0.003 & -0.002 & -0.002 & 0.004 & 0.004 & 0.000 & -0.001 & 0.000 \\
\hline 8 & 0.001 & 0.004 & -0.001 & -0.003 & 0.001 & 0.003 & 0.000 & 0.000 \\
\hline 9 & 0.003 & -0.002 & 0.001 & 0.000 & -0.002 & 0.000 & -0.001 & 0.000 \\
\hline \multicolumn{9}{|l|}{10} \\
\hline St. dev. Of & $\mathrm{Adi}=(0.002$ & 0.003 & 0.001 & 0.003 & 0.003 & 0.002 & 0.002 & $0.001)$ \\
\hline
\end{tabular}

Step 4: During interviews with four experts, $\mathrm{EP}_{1} l=(1,2,3,4)$, the requirements has been translated into the eight engineering characteristics $E_{j} j=(1,2,3,4,5,6,7,8)$. Table 6 shows details of the weight vector gathered from experts and we observe $\mathrm{v}=(.25, .25, .25, .25)$. As mentioned above, four product development experts $\mathrm{EP}_{1} \mathrm{l}=(1,2,3,4)$ evaluate the relationship matrix by using positive or negative linguistic variables, which reflect the correlation among ECs indirectly (Wang, 2010). Assume product development experts $\mathrm{EP}_{\mathrm{l}} \mathrm{l}=(1,2,3,4)$ give their judgments on the relationship between CRs and ECs using the following different ULLS:

$$
\begin{aligned}
& \mathrm{EP}_{1}, \mathrm{EP}_{2}: \mathrm{S}^{(4)}=\left\{\mathrm{S}_{-3}^{(4)}, \mathrm{S}_{-4 / 3}^{(4)}, \mathrm{S}_{-1 / 2}^{(4)}, \mathrm{S}_{0}^{(4)}, \mathrm{S}_{1 / 2}^{(4)}, \mathrm{S}_{4 / 3}^{(4)}, \mathrm{S}_{3}^{(4)}\right\} ; \\
& \mathrm{EP}_{3}, \mathrm{EP}_{4}: \mathrm{S}^{(3)}=\left\{\mathrm{S}_{-2}^{(3)}, \mathrm{S}_{-2 / 3}^{(3)}, \mathrm{S}_{0}^{(3)}, \mathrm{S}_{2 / 3}^{(3)}, \mathrm{S}_{2}^{(3)}\right\} .
\end{aligned}
$$

Then we get the initial group decision-making matrix $\widehat{R}=\left(\widehat{R}_{i j}\right)_{8 \times \dot{8}}$ Based on the weight vector $\mathrm{v}=(.25, .25, .25, .25)$ of the experts $\mathrm{EP}_{1} \mathrm{l}=(1,2,3,4)$, we use the method proposed by Wang and Xiong (2011) to aggregate the granularity-unified group decision-making information (Büyüközkan \& Feyzioğlu, 2005) into the collective linguistic decision matrix $\bar{R}=\left(R_{i j}\right)_{8 \times 8}$ which also is the final relationship matrix between CRs and ECs (Table 7)

\section{Table 6}

Engineering characteristics

\begin{tabular}{llcc}
\hline Symbol & Engineering characteristics & Symbol & engineering characteristics \\
\hline $\mathrm{EC}_{1}$ & $\begin{array}{l}1800 \text { warm off the amp (one-way with a minimum } \\
\text { amount) }\end{array}$ & $\mathrm{EC}_{5}$ & Thermal gradient generator (duplex) \\
$\mathrm{EC}_{2}$ & Lack of unusual noise during operation & $\mathrm{EC}_{6}$ & Serial packaging specification and generator \\
$\mathrm{EC}_{3}$ & Alternator noise test & $\mathrm{EC}_{7}$ & labeling \\
$\mathrm{EC}_{4}$ & Power Off and Battery Test & $\mathrm{EC}_{8}$ & $:$ Work piece appearance \\
\hline
\end{tabular}


Table 7

Final relationship matrix

\begin{tabular}{|c|c|c|c|c|c|c|c|c|}
\hline & $\mathrm{EC}_{1}$ & $\mathrm{EC}_{2}$ & $\mathrm{EC}_{3}$ & $\mathrm{EC}_{4}$ & $\mathrm{EC}_{5}$ & $\mathrm{EC}_{6}$ & $\mathrm{EC}_{7}$ & $\mathrm{EC}_{8}$ \\
\hline $\mathrm{CR}_{1}$ & $S^{(4)} 2.167$ & $S^{(4)} 0.833$ & $S^{(4)} 2.083$ & $S^{(4)} 1.125$ & $S^{(4)} 1.250$ & $S^{(4)}-0.583$ & $S^{(4)} 2.083$ & $S^{(4)}-0.083$ \\
\hline $\mathrm{CR}_{2}$ & $S^{(4)} 1.625$ & $S^{(4)}-0.333$ & $S^{(4)} 0.458$ & $S^{(4)} 1.333$ & $\mathrm{~S}_{3}^{(4)}$ & $S^{(4)}-0.583$ & $\mathrm{~S}_{2.5}^{(4)}$ & $S^{(4)}-0.083$ \\
\hline $\mathrm{CR}_{3}$ & $S^{(4)}-1.083$ & $S^{(4)} 0.625$ & $S^{(4)}-0.417$ & $S^{(4)}-1.083$ & $S^{(4)}-0.583$ & $\mathrm{~S}_{3}^{(4)}$ & $S^{(4)}-0.333$ & $S^{(4)} 2.250$ \\
\hline $\mathrm{CR}_{4}$ & $S^{(4)} 1.583$ & $S^{(4)} 2.083$ & $S^{(4)} 2.500$ & $S^{(4)} 1.875$ & $S^{(4)} 2.083$ & $S^{(4)} 1.167$ & $\mathrm{~S}_{3}^{(4)}$ & $S^{(4)} 0.708$ \\
\hline $\mathrm{CR}_{5}$ & $S^{(4)}-1.333$ & $S^{(4)} 0.458$ & $S^{(4)}-0.375$ & $S^{(4)}-1.083$ & $S^{(4)}-0.083$ & $S^{(4)} 1.667$ & $S^{(4)} 0.042$ & $S_{3}^{(4)}$ \\
\hline $\mathrm{CR}_{6}$ & $S^{(4)}-0.5$ & $S^{(4)} 0.708$ & $S^{(4)}-0.750$ & $S^{(4)} 0.5$ & $S^{(4)} 0.375$ & $S^{(4)}-0.917$ & $S^{(4)} 1.458$ & $S^{(4)} 0.208$ \\
\hline $\mathrm{CR}_{7}$ & $S^{(4)}-0.875$ & $S^{(4)}-0.042$ & $S^{(4)}-0.625$ & $S^{(4)}-0.833$ & $S^{(4)}-0.333$ & $S^{(4)} 0.917$ & $S^{(4)}-0.667$ & $S^{(4)} 1.167$ \\
\hline $\mathrm{CR}_{8}$ & $\mathrm{~S}^{(4)}{ }_{1.583}$ & $S^{(4)}{ }_{1.167}$ & $\mathrm{~S}^{(4)}{ }_{0.958}$ & $S^{(4)}{ }_{1.167}$ & $S^{(4)}{ }_{1.167}$ & $S^{(4)}-0.083$ & $S_{2.5}^{(4)}$ & $S^{(4)}-0.208$ \\
\hline
\end{tabular}

Step 5: Create the initial house of quality by using elements of a linguistic relationship matrix and final importance of CRs which has been obtained in the period 9 and obtain priority ratings of Ecs (Fig. 6)

\begin{tabular}{|c|c|c|c|c|c|c|c|c|c|}
\hline CR & FI & $\mathrm{EC}_{1}$ & $\mathrm{EC}_{2}$ & $\mathrm{EC}_{3}$ & $\mathrm{EC}_{4}$ & $\mathrm{EC}_{5}$ & $\mathrm{EC}_{6}$ & $\mathrm{EC}_{7}$ & $\mathrm{EC}_{8}$ \\
\hline $\mathrm{CR}_{1}$ & 0.039 & $S^{(4)} 2.167$ & $\mathrm{~S}^{(4)} 0.833$ & $\mathrm{~S}^{(4)}{ }_{2.083}$ & $S^{(4)}{ }_{1.125}$ & $\mathrm{~S}^{(4)}{ }_{1.250}$ & $S^{(4)}-0.583$ & $S^{(4)}{ }_{2.083}$ & $S^{(4)}-0.083$ \\
\hline $\mathrm{CR}_{2}$ & 0.025 & $S^{(4)}{ }_{1.625}$ & $S^{(4)}-0.333$ & $S^{(4)} 0.458$ & $S^{(4)} 1.333$ & $S_{3}^{(4)}$ & $S^{(4)}-0.583$ & $\mathrm{~S}^{(4)} 2.5$ & $S^{(4)}-0.083$ \\
\hline $\mathrm{CR}_{3}$ & 0.011 & $S^{(4)}{ }_{-1.083}$ & $S^{(4)}{ }_{0.625}$ & $S^{(4)}-0.417$ & $S^{(4)}-1.083$ & $S^{(4)}-0.583$ & $\mathrm{~S}_{3}^{(4)}$ & $S^{(4)}-0.333$ & $\mathrm{~S}^{(4)} 2.250$ \\
\hline $\mathrm{CR}_{4}$ & 0.026 & $\mathrm{~S}^{(4)}{ }_{1.583}$ & $S^{(4)}{ }_{2.083}$ & $S^{(4)}{ }_{2.500}$ & $\mathrm{~S}^{(4)}{ }_{1.875}$ & $\mathrm{~S}^{(4)}{ }_{2.083}$ & $S^{(4)}{ }_{1.167}$ & $S_{3}^{(4)}$ & $S^{(4)} 0.708$ \\
\hline $\mathrm{CR}_{5}$ & 0.028 & $S^{(4)}-1.333$ & $S^{(4)} 0.458$ & $S^{(4)}-0.375$ & $S^{(4)}-1.083$ & $S^{(4)}-0.083$ & $S^{(4)} 1.667$ & $S^{(4)} 0.042$ & $\mathrm{~S}_{3}^{(4)}$ \\
\hline $\mathrm{CR}_{6}$ & 0.027 & $S^{(4)}-0.5$ & $S^{(4)} 0.708$ & $S^{(4)}-0.750$ & $S^{(4)} 0.5$ & $S^{(4)} 0.375$ & $S^{(4)}-0.917$ & $S^{(4)}{ }_{1.458}$ & $\mathrm{~S}^{(4)} 0.208$ \\
\hline $\mathrm{CR}_{7}$ & 0.026 & $S^{(4)}-0.875$ & $S^{(4)}-0.042$ & $S^{(4)}-0.625$ & $S^{(4)}-0.833$ & $S^{(4)}-0.333$ & $S^{(4)} 0.917$ & $S^{(4)}-0.667$ & $S^{(4)}{ }_{1.167}$ \\
\hline $\mathrm{CR}_{8}$ & 0.008 & $S^{(4)} 1.583$ & $S^{(4)} 1.167$ & $\mathrm{~S}_{0.958}^{(4)}$ & $S^{(4)} 1.167$ & $S^{(4)}{ }_{1.167}$ & $S^{(4)}{ }_{-0.083}$ & $\mathrm{~S}_{2.5}^{(4)}$ & $S^{(4)}-0.208$ \\
\hline Absolute scores & & 0.093 & 0.125 & 0.114 & 0.085 & 0.180 & 0.071 & 0.261 & 0.156 \\
\hline Relative scores & & 0.086 & 0.115 & 0.105 & 0.078 & 0.166 & 0.065 & 0.241 & 0.144 \\
\hline RANK & & 6 & 4 & 5 & 7 & 2 & 8 & 1 & 3 \\
\hline
\end{tabular}

FI: Final importance

Fig 6. initial House of Quality

Here, for convenience, there is a simplification. First according to the prioritizing of engineering characteristics, the five most important engineering characteristics are selected and continue working to be followed by five EC. Second, the engineering characteristics of each customer's estimated needs are ranked from 1 to 8 based on the value of $\alpha$ from $S_{\alpha}^{(k)}$ and then each of these ranks is deducted from maximum rank 8 . Any engineering characteristic with low rank in estimating customer requirements is considered with the highest priority. Then the elements of the relationship matrix with the use of Eq. (1) are normalized and the result is shown in Fig. 7

\begin{tabular}{cccccccc}
\hline CR & FI & EC2 & EC3 & EC5 & EC7 & EC8 \\
\hline$C_{1}$ & $\mathbf{0 . 0 3 9}$ & 0.217 & 0.261 & 0.217 & 0.217 & 0.087 \\
& $\mathrm{CR}_{2}$ & $\mathbf{0 . 0 2 5}$ & 0.000 & 0.211 & 0.368 & 0.316 & 0.105 \\
$\mathrm{CR}_{3}$ & $\mathbf{0 . 0 1 1}$ & 0.231 & 0.154 & 0.000 & 0.154 & 0.462 \\
& $\mathrm{CR}_{4}$ & $\mathbf{0 . 0 2 6}$ & 0.226 & 0.226 & 0.194 & 0.226 & 0.129 \\
& $\mathrm{CR}_{5}$ & $\mathbf{0 . 0 2 8}$ & 0.118 & 0.176 & 0.118 & 0.176 & 0.412 \\
\hline $\mathrm{CR}_{6}$ & $\mathbf{0 . 0 2 7}$ & 0.286 & 0.000 & 0.214 & 0.286 & 0.214 \\
& $\mathrm{CR}_{7}$ & $\mathbf{0 . 0 2 6}$ & 0.111 & 0.111 & 0.111 & 0.111 & 0.556 \\
\hline $\mathrm{CR}_{8}$ & $\mathbf{0 . 0 0 8}$ & 0.273 & 0.227 & 0.182 & 0.273 & 0.045 \\
\hline & Priority ECj & & 0.0330 & 0.0326 & 0.0361 & 0.0417 & 0.0466 \\
& RANK & & 4 & 5 & $\mathbf{3}$ & $\mathbf{2}$ & 1 \\
\hline
\end{tabular}

FI: Final importance

Fig. 7. Simplified HoQ for Alternator set

Step 6: Compute the mean and standard deviation of forecasted ECs' priorities using Eq. (2) and Eq. (3), respectively. The resulting values, namely, the mean and the standard deviation of the forecasted ECs' priorities are shown in the DQFD (Fig. 8). What is worth highlighting here is the use of the forecasted ECs' priorities, which are derived from the future needs of the customer, as a basis for optimizing the ECs. 
Step 7: Check for first-order dominance using Fig. 8. For normal distribution, it is well-known that if $\mathrm{A} \sim \mathrm{N}\left(\mu_{\mathrm{A}}, \sigma_{\mathrm{A}}\right)$ and $\mathrm{B} \sim \mathrm{N}\left(\mu_{\mathrm{B}}, \sigma_{\mathrm{B}}\right)$, then A will first order stochastically dominates $\mathrm{B}$, or $\mathrm{A}>_{(1)} \mathrm{B}$, if and only if $\mu_{A}>\mu_{B}$ and $\sigma_{A}=\sigma_{B}$. Furthermore, A will second order stochastically dominate $B$, or $\mathrm{A}>_{(2)} \mathrm{B}$, if and only if $\mu_{\mathrm{A}} \geq \mu_{\mathrm{B}}$ and $\sigma_{\mathrm{A}} \leq \sigma_{\mathrm{B}}$. The overall dominance relationship is $E C_{8} \succ_{(1)} E C_{7} \succ_{(1)} E C_{5} \succ_{(1)} E C_{2} \succ_{(2)} E C_{3}$.

\begin{tabular}{|c|c|c|c|c|c|c|c|c|c|c|c|c|c|c|c|}
\hline & \multirow[b]{2}{*}{$\mathrm{EC} 2$} & \multirow[b]{2}{*}{ EC3 } & \multirow[b]{2}{*}{ EC5 } & \multirow[b]{2}{*}{ EC7 } & \multicolumn{8}{|c|}{ Competitor } & \multicolumn{3}{|c|}{ Forecasted $(\mathrm{t}=10)$} \\
\hline & & & & & EC8 & own & 1 & 2 & 3 & 4 & $\mathrm{~T}$ & RI & IR & StDev & Var. \\
\hline $\mathrm{CR}_{1}$ & 0.217 & 0.261 & 0.217 & 0.217 & 0.087 & 6 & 5 & 5 & 5 & 7.5 & 9.5 & 1.583 & 0.037 & 0.002 & 0.000004 \\
\hline $\mathrm{CR}_{2}$ & 0.000 & 0.211 & 0.368 & 0.316 & 0.105 & 4.75 & 6 & 6 & 6.25 & 7 & 6.8 & 1.432 & 0.026 & 0.003 & 0.000009 \\
\hline $\mathrm{CR}_{3}$ & 0.231 & 0.154 & 0.000 & 0.154 & 0.462 & 5.50 & 7.5 & 7.5 & 6.5 & 5.25 & 5.8 & 1.055 & 0.010 & 0.001 & 0.000001 \\
\hline $\mathrm{CR}_{4}$ & 0.226 & 0.226 & 0.194 & 0.226 & 0.123 & 3.50 & 5 & 5 & 6.75 & 5.75 & 5.4 & 1.543 & 0.026 & 0.003 & 0.000009 \\
\hline $\mathrm{CR}_{5}$ & 0.118 & 0.176 & 0.118 & 0.176 & 0.412 & 7.50 & 5.2 & 5.25 & 5.75 & 7.25 & 8.3 & 1.107 & 0.029 & 0.003 & 0.000009 \\
\hline $\mathrm{CR}_{6}$ & 0.286 & 0.000 & 0.214 & 0.286 & 0.214 & 8.00 & 4.25 & 4.25 & 3.25 & 4 & 9 & 1.125 & 0.027 & 0.002 & 0.000004 \\
\hline $\mathrm{CR}_{7}$ & 0.111 & 0.111 & 0.111 & 0.111 & 0.556 & 3.25 & 6 & 6 & 7.25 & 5.5 & 5.5 & 1.692 & 0.027 & 0.002 & 0.000004 \\
\hline $\mathrm{CR}_{8}$ & 0.273 & 0.227 & 0.182 & 0.273 & 0.045 & 6.25 & 6.5 & 6.5 & 6.00 & 5.25 & 7.6 & 1.216 & 0.008 & 0.001 & 0.000001 \\
\hline Mean of forecasted ECj priority & 0.0325 & 0.0325 & 0.0363 & 0.0417 & 0.0469 & & & & & & & & & & \\
\hline StDev of forecasted ECj priority & 0.0025 & 0.0027 & 0.0029 & 0.0031 & 0.0031 & & & & & & & & & & \\
\hline
\end{tabular}

Fig. 8. The DQFD for Alternator set

Step 8: Stochastically order the ECs according to the dominance relationship result, and construct a resource allocation constraint based on the stochastic ordering. The stochastic ordering result is $E C_{8} \succ_{(1)} E C_{7} \succ_{(1)} E C_{5} \succ_{(1)} E C_{2} \succ_{(2)} E C_{3}$. This simply says that all decision makers, who prefer more to less and are risk-averse, will agree with the stochastic ordering. Consequently, more resources and efforts should be allocated to those ECs that are more preferred. The optimization model described in Eqs. (9-13) is used for illustrating the proposed methodology. Suppose that there is an amount of $\$ 18$ reserved for this year's quality improvement efforts in the department. This available budget should be properly allocated for the fulfillment of the ECs so that the future total customer satisfaction level will be maximized. According to the department's decision, the cost of improvement of each EC to achieve its maximum possible target value (best possible state), namely, the fulfillment cost $\left(\mathrm{C}_{\mathrm{j}}\right)$ is $\$ 7, \$ 6, \$ 6, \$ 11, \$ 9$, for $\mathrm{EC}_{2}, \mathrm{EC}_{3}, \mathrm{EC}_{5}, \mathrm{EC}_{7}, \mathrm{EC}_{8}$, respectively (variables $\mathrm{X}_{1}, \mathrm{X}_{2}, \mathrm{X}_{3}, \mathrm{X}_{4}, \mathrm{X}_{5}$ ). Then, for the sake of simplicity, the minimum satisfaction level for each CR (Xie et al., 2003) is assumed to be the same, that is, $50 \%$, or $\mathrm{SL}_{\mathrm{i}}=0.5, \forall \mathrm{i}=1, \ldots, 8$. It is again assumed that there is no difference in the amount of EC fulfillment, thus $\delta_{\mathrm{r}}=0, \forall \mathrm{r}=1, \ldots, 4$. Note that the last value of the subscript $r$, that is, four $(r=4)$, denotes the number of the stochastic dominance constraints used to represent the stochastic ordering result (see Eq. (12)). The complete formulation according to the total customer satisfaction optimization model in Eqs. (9-13) is as follows.

Maximize $\mathrm{Z}=0.005 \mathrm{X}_{1}+0.005 \mathrm{X}_{2}+0.006 \mathrm{X}_{3}+0.004 \mathrm{X}_{4}+0.005 \mathrm{X}_{5}$

Subject to:

$\mathrm{X}_{1}+\mathrm{X}_{2}+\mathrm{X}_{3}+\mathrm{X}_{4}+\mathrm{X}_{5} \leq 18$

$0.031 \mathrm{X}_{1}+0.044 \mathrm{X}_{2}+0.036 \mathrm{X}_{3}+0.020 \mathrm{X}_{4}+0.010 \mathrm{X}_{5} \geq 50 \%$

$0.035 \mathrm{X}_{2}+0.061 \mathrm{X}_{3}+0.029 \mathrm{X}_{4}+0.012 \mathrm{X}_{5} \geq 50 \%$

$0.033 \mathrm{X}_{1}+0.026 \mathrm{X}_{2}+0.014 \mathrm{X}_{4}+0.051 \mathrm{X}_{5} \geq 50 \%$

$0.032 \mathrm{X}_{1}+0.038 \mathrm{X}_{2}+0.032 \mathrm{X}_{3}+0.021 \mathrm{X}_{4}+0.014 \mathrm{X}_{5} \geq 50 \%$

$0.017 \mathrm{X}_{1}+0.029 \mathrm{X}_{2}+0.020 \mathrm{X}_{3}+0.016 \mathrm{X}_{4}+0.046 \mathrm{X}_{5} \geq 50 \%$

$0.041 \mathrm{X}_{1}+0.036 \mathrm{X}_{3}+0.026 \mathrm{X}_{4}+0.024 \mathrm{X}_{5} \geq 50 \%$

$0.016 \mathrm{X}_{1}+0.019 \mathrm{X}_{2}+0.019 \mathrm{X}_{3}+0.010 \mathrm{X}_{4}+0.062 \mathrm{X}_{5} \geq 50 \%$

$0.039 X_{1}+0.038 X_{2}+0.030 X_{3}+0.025 X_{4}+0.005 X_{5} \geq 50 \%$

$0.111 \mathrm{X}_{5}-0.91 \mathrm{X}_{4} \geq 0$

$0.91 \mathrm{X}_{4}-0.167 \mathrm{X}_{3} \geq 0$ 
$0.167 \mathrm{X}_{3}-0.143 \mathrm{X}_{1} \geq 0$

$0.143 \mathrm{X}_{1}-0.167 \mathrm{X}_{2} \geq 0$

$0 \leq 0.143 \mathrm{X}_{1} \leq 1,0 \leq 0.167 \mathrm{X}_{2} \leq 1,0 \leq 0.167 \mathrm{X}_{3} \leq 1,0 \leq 0.091 \mathrm{X}_{4} \leq 1,0 \leq 0.111 \mathrm{X}_{5} \leq 1$

The solution for the above optimization model is shown in Table 6. An example of interpreting the result is as follows. An amount of $\$ 6.241$ should be allocated to $\mathrm{EC}_{8}$, which results in $69.34 \%$ fulfillment of its target value, while the amount of $\$ 1.023$ should be allocated to $E C_{3}$. This solution is fully consistent with the stochastic $\left(E C_{8}>_{(1)} E C_{7}>_{(1)} E C_{5}>_{(1)} E C_{2}>_{(2)} E C_{3}\right)$ since $E C_{8}$ is the most preferred one, while $\mathrm{EC}_{3}$ is the least preferred. The total customer satisfaction that can be obtained from this solution is $8.7 \%(\mathrm{Z}=8.7 \%)$.

Table 6

Optimal results with SD constraint

With SD Constraint $(\mathrm{Z}=8.7 \%)$

\begin{tabular}{cccccc} 
Variable & $\mathrm{X}_{1}$ & $\mathrm{X}_{2}$ & $\mathrm{X}_{3}$ & $\mathrm{X}_{4}$ & $\mathrm{X}_{5}$ \\
\hline Allocation & 3.131 & 1.023 & 2.684 & 4.921 & 6.241 \\
Fulfillment & $44.72 \%$ & $17.05 \%$ & $44.73 \%$ & $\% 44.73$ & $\% 69.34$ \\
\hline
\end{tabular}

Now, suppose if the stochastic dominance constraints, are relaxed and the model is solved once again using the software (Hadar \& Russell, 1974). The purpose of this paper is to illustrate what would happen if one ignored the future uncertainty factor in the customer needs. The result is shown in Table 7. In contrast to the previous result, the result, although having a slightly higher customer satisfaction value $(Z=9.6 \%)$, is totally not in agreement with the stochastic ordering. For instance, $\mathrm{EC}_{3}$, which is the least preferred one, has $53.55 \%$ level of fulfillment while none of the resource is allocated to $\mathrm{EC}_{7}$, which is much more preferred than $\mathrm{EC}_{3}$.

Table 7

Optimization results without SD constraint

\begin{tabular}{cccccc}
\hline & & Without SD Constraint $(\mathrm{Z}=9.6 \%)$ & $\mathrm{X}_{4}$ & $\mathrm{X}_{5}$ \\
Variable & $\mathrm{X}_{1}$ & $\mathrm{X}_{2}$ & $\mathrm{X}_{3}$ & 0.000 & 4.438 \\
\hline Allocation & 4.884 & 3.213 & 5.466 & $0 \%$ & $49.31 \%$ \\
\hline Fulfillment & $69.77 \%$ & $53.55 \%$ & $91.1 \%$ & \\
\hline
\end{tabular}

In sum, the optimization model results in an optimal policy to allocate the department yearly budget. The policy may be considered as 'optimal' not only because it has taken into account the resource limitation, but also because it could consider the future customer's needs along with their uncertainty. Another finding is that unless the future uncertainty factor, which is represented by the variance of the forecasting residual, in the CRs is taken into account, it is very likely that one might end up with a fallacious allocation policy with respect to the decision maker's attitude towards risk in the future needs. After optimizing the fulfillment of each EC, the QFD team may use the result for other subsequent downstream analysis.

\section{Discussions}

\subsection{Selection of forecasting technique}

There are at least two reasons on why the double exponential smoothing method is selected. First, it is suitable for the situation when there is only a limited amount of historical data. Second, it is relatively simple and time-efficient compared with other time series methods, especially for modeling the dynamics of priorities based on the proposed method using linguistic variables. It is possible that the double exponential smoothing method may end up with errors which would not follow a process which is normally, independently, identically distributed (NIID) with a zero mean value and a constant variance. In such case, other predicting techniques, such as multivariate time series 
technique, are called for. What is more important here is the fact that a proper and adequate forecasting technique will result in a process which is normally, independently, identically distributed (NIID) with a zero mean value and a constant variance, of which variance is proposed as the measure of future uncertainty of the forecasted points.

\section{Conclusions}

The aim of this paper was to propose a novel systematic methodology to deal with the customer needs' dynamics in QFD. Specifically, the contribution of this work can be summarized into four points. First, it applied the linguistic variables to get preferences of customers and experts to detect the relative importance of customer requirements (CRs) and relationships between customer requirements and engineering characteristics (ECs). Second, it also proposed the use of a forecasting technique. Third, it described more comprehensively on how future uncertainty in the weights of customer needs could be estimated and transmitted into the design attributes. Fourth, it proposed an application of a quantitative approach, which takes into account the decision maker's attitude towards risk to optimize the QFD decision making analysis. The proposed methodology placed a heavy emphasis on monitoring and following the change of customer's preference over time. It is because a timely update of customer information may provide useful feedback for the company to react differently and continuously over time as to formulate strategies or to upgrade its products or services to meet the changing needs of its customer.

From a methodological standpoint, there are three areas, which might be worth investigating for future work. First, it might be interesting to investigate the dynamics of other HoQ's elements apart from the VOC. Second, it is a further investigation on how one may deal with the condition where there is a new customer need (VOC) or exclusion of an old one as the passage of time. Third, in the use of stochastic dominance approach in QFD, how one may know precisely the percentage of the resources to be allocated in the stochastically-ordered ECs remains a challenging issue to be addressed. Furthermore, if the QFD team has a risk seeking attitude, the proposed stochastic dominance approach may no longer apply. From a practical standpoint, a worth noting aspect is the difference between the real rate of change of customer preference and the observation period, that is, how often the data should be collected. For example, it would be of little value if the customer needs' information is collected monthly, while the real change rate were on yearly basis. Finally, more realworld applications of the proposed methodology would certainly be of great value to showcase the usefulness of the dynamic QFD in practice.

\section{References}

Akao, Y. (1990). Quality function deployment: Integrating customer requirements into product design. Cambridge, MA: Productivity Press.

Bhattacharya, S., Krishnan, V., \& Mahajan, V. (1998). Managing new product definition in highly dynamic environments. Management Science, 44(11), S50-S64.

Bordogna, G., Fedrizzi, M., \& Pasi, G. (1997). A linguistic modeling of consensus in group decision making based on OWA operators. IEEE Transactions on Systems, Man and Cybernetics - Part A: Systems and Humans, 27(1), 126-133.

Büyüközkan, G., \& Feyzioğlu, O. (2005). Group decision making to better respond customer needs in software development. Computers \& Industrial Engineering, 48(2), 427-441.

Cristiano, J. J., Liker, J. K., \& White III, C. C. (2001). Key factors in the successful application of quality function deployment (QFD). Engineering Management, IEEE Transactions on, 48(1), 8195.

Cohen, L., \& Cohen, L. (1995). Quality function deployment: how to make QFD work for you (p. 348). Reading, MA: Addison-Wesley. 
Hadar, J., \& Russell, W. R. (1974). Decision making with stochastic dominance. An expository review. Omega, 2(3), 365-377.

Han, C., Kim, J., \& Choi, S. (2004). Prioritizing engineering characteristics in quality function deployment with incomplete information: A linear partial ordering approach. International Journal of Production Economics, 91(3), 235-249.

Herrera, F., Herrera-Viedma, E., \& Martínez, L. (2000). A fusion approach for managing multigranularity linguistic term sets in decision-making. Fuzzy Sets and Systems, 114(1), 43-58.

Ho, E. S. S. A., Lai, Y. J., \& Chang, S. I. (1999). An integrated group decision-making approach to quality function deployment. IIE Transactions, 31(6), 553-567.

Kim, D., \& Kim, K .(2009). Robustness indices and robust prioritization in QFD. Expert Systems with Applications, 36, 2651-2658.

Köksal, G., \& Eğitman, A. (1998). Planning and design of industrial engineering education quality. Computers \& Industrial Engineering, 35(3), 639-642.

Kuo, T., Wu, H., \& Shieh, J. (2009). Integration of environmental considerations in quality function deployment by using fuzzy logic. Expert Systems with Applications, 36, 7148-7156.

Kwong, C. K., \& Bai, H. (2003). Determining the importance weights for the customer requirements in QFD using a fuzzy AHP with an extent analysis approach. IIE Transactions, 35, 619-626.

Levy, H. (1998). Stochastic dominance. Investment decision making under uncertainty. Norwell, MA: Kluwer Academic Publishers.

Li, Y., Huang, M., Chin, K., Luo, X., \& Han, Y. (2011). Integrating preference analysis and balanced scorecard to product planning house of quality. Computers \& Industrial Engineering, 60, 256-268.

Li, Y., Tang, J., \& Luo, X. (2010). An ECI-based methodology for determining the final importance ratings of customer requirements in MP product improvement. Expert Systems with Applications, $37,6240-6250$

Liu, H. (2009). The extension of fuzzy QFD: From product planning to part deployment. Expert Systems with Applications, 36, 11131-11144.

Prasad, B. (1998). Review of QFD and related deployment techniques. Journal of Manufacturing Systems, 17(3), 221-234.

Raharjo, H., Xie, M. C., \& Brombacher, A. (2011). A systematic methodology to deal with the dynamics of customer needs in Quality Function Deployment. Expert Systems with Applications, $38,3653-3662$.

Wang, X. \& Xiong, W (2011). An integrated linguistic-based group decision-making approach for quality function deployment. Expert Systems with Applications, 38, 14428-14438.

$\mathrm{Xu}, \mathrm{Z}$. (2009). An automatic approach to reaching consensus in multiple attribute group decision making. Computers \& Industrial Engineering, 56(4), 1369-1374.

Zhang, Z., \& Chu, X. (2009). Fuzzy group decision-making for multi-format and multi-granularity linguistic judgments in quality function deployment. Expert Systems with Applications, 36(5), 9150-9158. 